\title{
Esophagus Progression GvHD
}

National Cancer Institute

\section{Source}

National Cancer Institute. Esophagus Progression GVHD. NCI Thesaurus. Code C126728.

An NIH esophagus score that has increased by 1 or more points, except 0 to 1 . 